\title{
Green Cleaning for the Sri Lankan Healthcare Sector: Critical Support Factors and Barriers
}

\author{
A.K.N.E. Rathnasiri \& Poornima Shridharran \\ Centre for Cities, \\ University of Moratuwa, \\ Sri Lanka
}

\begin{abstract}
The extensive use of cleaning chemicals and disinfectants in the healthcare industry in recent years has raised concerns over the effectiveness of conventional cleaning in creating safe and healthy environments. Green cleaning was introduced in the 1980s as a substitute for conventional cleaning. Green cleaning denotes methods and products of cleaning, which incorporate environmentally friendly ingredients that preserve human health and environmental quality. Even though there is a rapid adoption of green cleaning in many countries, Sri Lanka seems to fall behind in shifting to green cleaning.

This research focuses on investigating the factors that either support or obstruct green cleaning in Sri Lanka. A qualitative research involving interviews of experts were conducted among cleaning related managerial personals and the data was analyzed through content analysis. The paper concludes that the most notable support factors were proper awareness, training and education, top management commitment and availability of green cleaning legislation and guidelines. The barriers were lack of awareness of the stakeholders, lack of top management commitment, lack of technical advancement in the country and lack of government support.
\end{abstract}

Keywords: Green cleaning, Critical success factors, Barriers

\section{Introduction}

Among the support services of many organizations, cleaning is recognized as a main service and the awareness of this service is significant for effective building operations (Klungseth \& Olsson, 2013). Cleaning is compulsory in ensuring a healthy environment but is also a costly service (Darly \& Pitt, 2012; Klungseth \& Ollson, 2013).

The traditional cleaning methods include physical removal of micro-organisms using a detergent solution or a disinfectant (Boyce, 2016). The cleaning workers use complex chemical mixtures of cleaning and disinfectant products for equipment cleaning, floor cleaning, instrument cleaning and fixed surface cleaning (Saito et al., 2015). Even though conventional cleaning practices offer sound methods for effective cleaning, they do come with a number of issues. The most significant issue is the intensified exposure and the risk of health effects including respiratory illnesses among the cleaning personals due to traditional cleaning practices (Quinn, et al., 2015). Evidence shows that respiratory illnesses and other acute and chronic health effects are caused by the exposure to cleaning chemicals (Dumas et al., 2017: Quinn et al., 2015: Zingg et al., 2015: Saito et al., 2015: Moual et al., 2013: Arif\&Delclos, 2012: Nazarof\&Weschler, 2004).

Due to the elevated risk of respiratory effects on cleaning workers, the need for a safer alternative has been recognised (Dumas et al., 2017: Dancer, 2016). The adverse effect on the environment has also encouraged the products, which has a lesser impact on the biological system (Dancer, 2011). As a solution for the increasing health effects of exposure to cleaning and disinfecting products, hospitals seek less toxic, and disinfecting products and methods often called green cleaning (Quinn, et al., 2015). Most of the owners, employers and building managers are shifting towards green cleaning chemicals with the expectation of providing a safer environment for the workers (OSHA/NIOSH Infosheet, 2012). Green cleaning denotes the 
methods and products of cleaning, which incorporate environmentally-friendly ingredients that preserve human health and environmental quality (Sabharwal, 2015). Green cleaning is interrelated to the sustainability concept (Corbett, et al., 2017). This concept aims to reduce the negative impact on people and environment caused by cleaning (Quan, et al., 2011). However, there is no agreed definition for green cleaning (Spruce, 2017: Quinn et al., 2015: Quan et al., 2011), although it refers to the avoidance of chemically-reactive toxins (Sabharwal, 2015).

Despite the nearly two decades of successful history and the popularity of the green cleaning concept, Sri Lanka is still behind in adopting this practice. Hence, it is significant to properly identify the Critical Success Factors (CSF) and barriers for green cleaning. This study aims to identify the CSF and green cleaning barriers prevailing in Sri Lanka through a qualitative approach.

\subsection{Green Cleaning}

Green cleaning means a systematic, environmentally friendly cleaning approach, which not only includes the use of green products according to the chemical composition and also other attributes (Quan et al., 2011). It refers generally to environmental cleaning approaches that aim to reduce the harmful effects of cleaning on human health and the environment while maintaining or improving the cleanliness of the healthcare environment for infection prevention (Environmental Protection Agency [EPA], 2010). In addition, EPA mentions that selection of green cleaners, the use of safer alternative cleaning methods and changes in building design and operations as the approaches of green cleaning. Moreover, green products often carry the properties of limited exposure to the product using techniques such as better automatic dilution systems, recyclable or already recycled packaging and reduced energy usage for transportation which used concentrations along with favourable ingredients (Espinoza et al., 2011). The environmentally friendly manufacturing, packaging, and distribution of cleaning products are also referred under green cleaning (Sabharwal, 2015). According to Quan et al. (2011), the selection of surface materials that are easier to clean, performance improvement of cleaning staff and microfiber usage can be mentioned as green cleaning practices. Table 1 lists out the categories of green cleaning.
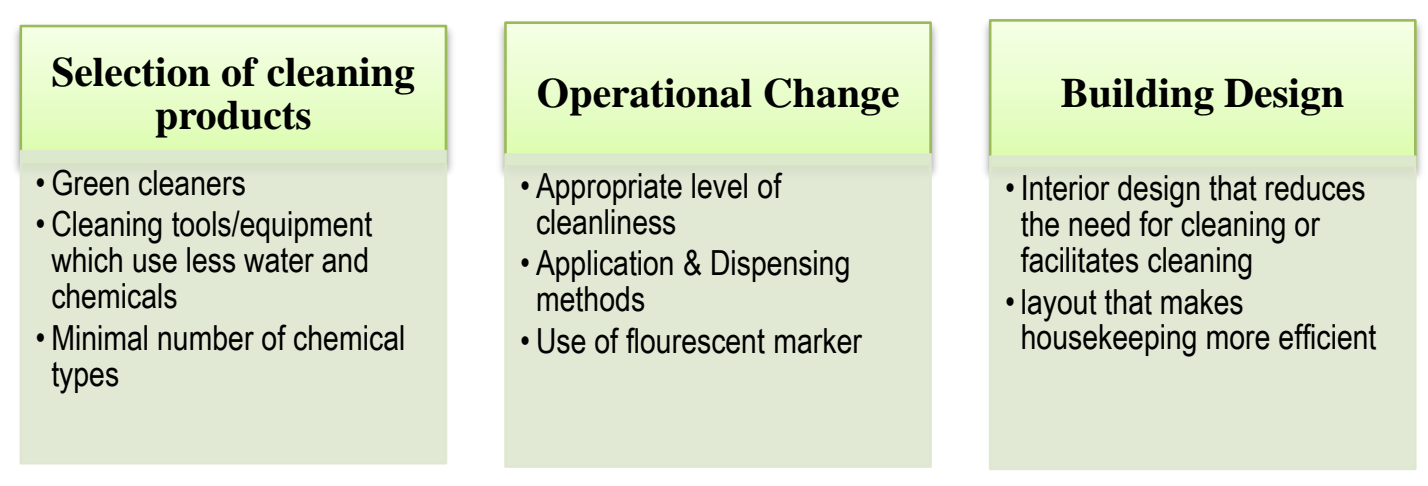

Figure 1: Green cleaning methods

Adopted from: (Quan et al., 2011)

\subsection{Success factors of green cleaning}

Every project or a new concept has a set of success factors that will assist in the effective implementation in the industry or any given context. Considering the green cleaning domain, it has numerous stakeholders with different objectives and it is therefore difficult to develop a single strategy to adopt this novel concept. In the context of difficulties of applying a novel method or concept, it is significant to identify a set of success factors and manage them properly. In order to identify them, a survey of scholarly articles published in the Scopus data base from 1995 to 2020 was done. Scopus is one of the two (web of science) most widespread databases (Guz \& Rushchitsky , 2009) which is also popular as the largest searchable source of literature (Vieira \& Jose, 2009). Peer-reviewed papers published on Scopus database and relevant keywords were used to conduct the study since it contains the most credible and recent journal publications (Chadegani, et al., 2013; Vieira \& Jose, 2009). 
Articles relevant to building maintenance were only considered to identify the factors of success or failure of green maintenance. Thirty four (34) articles written based on green cleaning domain of buildings were found and only a few articles discussed the CSF of green maintenance. Table 1 shows the success factors of green cleaning found by scholars in the domain of green cleaning. Atamamen et al., (2016) have conducted a comprehensive study to identify the factors that support the implementation of green cleaning.

Table 1: Green Cleaning Success Factors

Source: Authors

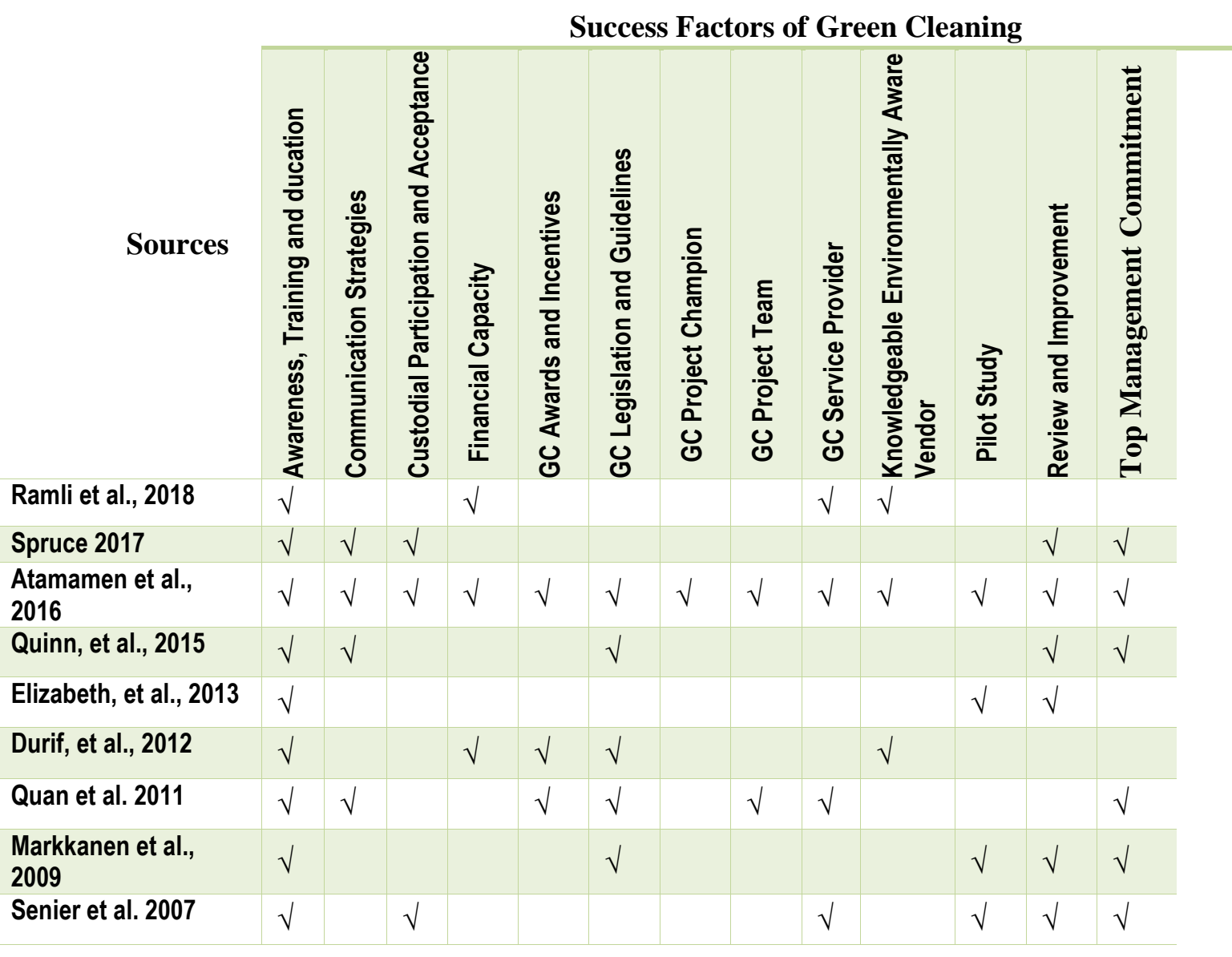

\section{Research Methodology}

To pursue the research aim of identifying the underline factors of green cleaning in Sri Lanka, a qualitative approach has been employed. The most distinguishing feature of this approach is that it allows the researcher to delve into the research problem from the study partners' perspective and based on that, fathom the interpretations and opinions of them (Hennink, et. Al., 2010). The research question and the subjective nature of the required data supported the selection of a qualitative approach. Even though the green cleaning concept has evolving since the 1980's in the global context, green cleaning accounted for a novel concept in Sri Lanka. Hence the difficulty of drawing a large sample of respondents was a limitation of the research.

The objectives of the research were to identify the concept of green cleaning and to determine barriers and enablers for the systematic application of green cleaning in the Sri Lankan healthcare sector. Initially, a comprehensive literature study was carried out to determine the CSF of green cleaning which applies to the global context. Secondly, to identify the barriers and CSF of green cleaning related to Sri Lanka, twelve (12) experts were interviewed. They included managerial personnel and green cleaning service providers. Semi-structured interviews were conducted to collect the data using an interview guideline. Hsieh and Shannon (2005) shows that content analysis provides subjective interpretations to the 
collected data using systematic coding and patterns and has been preferred by the academics to analyse text data. It is believed that qualitative data analysis through software adds a level of rigour to the process. In a qualitative approach, the nature of the responses received even to express similar ideas can be different due to multiple synonyms. Hence, it makes the recovery of all responses difficult (Welsh, 2002). Therefore, code-based content analysis using the NVivo software and manual content analysis were performed to analyze the research findings and to reach conclusions. Table 1 shows the respondent's profile of the research.

Table 2: Respondent's Profile

Source: Authors

\begin{tabular}{lll}
\hline \multicolumn{1}{c}{ Position } & Respondent's details & \\
& No of respondents & Healthcare Institute \\
\hline Facilities Manager & 2 & Private \\
\hline Executive Housekeeper & 4 & Private \\
\hline Maintenance Engineer & 1 & Private \\
\hline Quality Assurance Manager & 1 & Private \\
\hline Infection controller & 3 & Government \\
\hline Green Cleaning supplier & 1 & Private \\
\hline
\end{tabular}

\section{Data Analysis and Discussion}

\subsection{Critical Success Factors (CSF) of Green Cleaning applied to Sri Lanka}

CSF has the ability to guarantee successful competitive performance for an organisation if the factors identified are addressed satisfactorily. Prior identification of CSF is beneficial for managers in determining the factors which need management attention and focus. It ensures that significant elements will receive constant and careful management monitoring and controlling. Atamament et al., (2016) have produced a comprehensive set of green cleaning success factors which most of the other scholars agree upon. These identified success factors were presented to the interviewees to derive the most CSF of green cleaning which applies to Sri Lanka.

In Nvivo coding structures, the collected data is transcribed and imported to the software where the numerical values were derived by counting the number of time a specific word or a set of words appeared under a specific theme or a question. Nivivo analysis assists in conducting data analysis in a transparent and accurate manner. In generated coding structures, the files column displays the number of respondents who mentioned the sub node. The references column shows all the references that have been coded under the mother node.

Fig. 1 shows the green cleaning critical success factors (CSF) agreed by the respondents and the number of times they have been mentioned. All the respondents emphasized having awareness, training and education as the most important CSF. Green cleaning legislation, guidelines and top management commitment were also mentioned by 10 out of 12 respondents. 8 out of 12 respondents mentioned that custodial participation and acceptance, financial capacity and having knowledgeable environmentally aware vendors as CSF of green cleaning applicable to Sri Lanka. Only 4 respondents have identified green cleaning provider and pilot study as success factors while the least mentioned factors were the communication strategies, green cleaning awards and incentives, green cleaning project team and review and improvement.

Proper awareness from all the community members including management personnel, workers, suppliers, government, students and researchers were highlighted to successfully popularize the true meaning of green cleaning. According to the respondents; "integrating the value of green cleaning and associated benefits to the educational system to ensure that young population has a firm grasp on the fundamentals of green cleaning which will influence them to adapt these safer alternatives in the future" is an important issue. 


Critical Success Factors of Green Cleaning
\begin{tabular}{|l|r|r|}
\hline Name & Files & $\nabla$ References \\
\hline Critical Success Factors of Green Cleaning & 12 & 76 \\
\hline Awareness, Training and Education & 12 & 12 \\
\hline Top Management Commitment & 10 & 10 \\
\hline GC Legislation and Guidelines & 10 & 10 \\
\hline Custodial Participation and Acceptance & 8 & 8 \\
\hline Financial Capacity & Knowledgeable Environmentally Aware Vendor & 8 \\
\hline GC Service Provider & 8 & 8 \\
\hline Pilot Study & 4 & 4 \\
\hline Communication Strategies & 4 & 4 \\
\hline GC Awards and Incentives & 3 & 3 \\
\hline GC Project Team & 3 & 3 \\
\hline
\end{tabular}

Figure 2: Code structure of CSF of green cleaning

It is highly important to provide necessary awareness for top managers to assist them in expanding their knowledge and understanding the green cleaning concept, implementation strategies and necessary resources to successfully implement the green cleaning programs. As highlighted by the respondents, not only the awareness but also the management support, commitment and continuous evolvement on par with the global trends are indispensable. Both literature and respondents agreed that government involvement and endorsements in green concepts are accelerating and stimulating the adoption of green cleaning. One of the respondents of the government sector emphasized that "especially in developing countries where public services play a major role in healthcare and sanitation, government approval and pioneering in a novel concept as green cleaning would provide a guarantee to the public in embracing this concept". Government initiatives followed by proper policies, guidelines and legislation enforcement is critical and will act as acertification process for professionals related to the cleaning industry.

Somehow, the cost is reported as an issue in green cleaning with regards to the initial cost of investment for purchasing quality products (Quan, et al., 2011). Since initial cost of green cleaning slightly accounted for higher capital compared to the conventional cleaning having a financial capacity to gradually shift to the safer alternative was discussed as a CSF. However, according to a facilities manager of private sector "compared to operational expenses and other expenses of a healthcare facility, cleaning expenses are low. Therefore, financial capacity is not an issue to convert from conventional cleaning process to green cleaning process compared to its deliverables in quality".

Custodial participation and acceptance have been cited as the second most important success factor by 10 out of 12 respondents. The significance was further elaborated since workers are the stakeholders who were directly involved with the cleaning tasks. Hence, their acceptance and positive responses are more important in the successful delivery of green cleaning than any other stakeholder.

Apart from the above CSF, conducting a pilot study and establishing proper communication channels were considered as considerable success factors of introducing green cleaning concept into contemporary healthcare cleaning. Providing green cleaning awards and incentives were the least mentioned success factors (3/12). As explained by the practitioners, Sri Lanka does not practice offering awards and incentives for attributes as such but highlighted the need for initiating. Reviewing and improving the green cleaning projects were only mentioned by a few respondents. Nevertheless, literature discussed review and improvement as a major success factor since the continuation of green cleaning practices depend on the results of the review and the corresponding adjustments to improve. As shown in Fig. 1, it was evident that literature-found CSF identically apply for the Sri Lankan context as well. 


\subsection{Barriers to apply green cleaning in Sri Lanka}

Barriers to Apply Green Cleaning in Sri Lanka Health Sector
\begin{tabular}{|l|r|r|}
\hline Name & Files & References \\
\hline Barriers to Apply Green Cleaning in Sri Lanka Health Sector & 12 & 12 \\
\hline Lack of awareness & 7 & 12 \\
\hline Lack of top management commitment & 6 & 7 \\
\hline Lack of technical advancement in the country & 6 & 6 \\
\hline Lack of involvement from government & 5 & 6 \\
\hline Lack of resources & 5 & 5 \\
\hline Risk of using green cleaning chemicals & 5 & 5 \\
\hline Poor attitudes of the workers & 5 & 5 \\
\hline Low level of quality of cleaning & 4 & 5 \\
\hline Expensive green cleaning products & 4 & 4 \\
\hline The less priority given to the innovations & 4 \\
\hline Lack of competitive market & 3 & 4 \\
\hline Lesser number of complaints receives & 2 & 3 \\
\hline Lack of third party certification for the products & 2 & 1 \\
\hline Comparativelty small chemical industry & 2 & 2 \\
\hline
\end{tabular}

Figure 3: Code structure of Barriers of green cleaning in Sri Lanka Source: Authors

As shown in Fig. 2, the highly mentioned barrier was the lack of awareness. It suggests that without sound knowledge of the concept, it is difficult to initiate the concept in Sri Lanka. The second most commented barrier was the lack of top management commitment. According to the respondents, lack of interest of management personnel as decision makers highly impact when implementing green cleaning practices. Lack of involvement from the government was discussed thirdly as one of the barriers. The term "involvement" was explained by the respondents as "involvement in educating the community on green cleaning, creating policies and regulations, increased attention to minimize environmental impact of cleaning chemicals and initiating the green cleaning adoption in government organizations". The discussed barriers were not identified in the literature. Hence it can be concluded that these barriers are exclusive to the Sri Lankan context.

The inadequate level of innovations and adaptation of new technologies of the country creates an environment where conventional practices emerge as the best method of work. As a developing country, Sri Lanka seems to lag behind in adopting new green technologies due to numerous reasons such as financial incapacities, lack of staff engagement and lack of awareness (Moramudali \& Manawadu, 2018). Poor attitudes of the custodians were discussed as one of the barriers. Similarly, Simcox et al., (2013) have identified poor attitude of the workers, lack of participant and janitorial resistance as barriers of green cleaning.

In addition, the lack of attention to the quality of cleaning and the risk of using green cleaning was discussed under barriers of green cleaning. The risk associated with adopting green cleaning was explained by the respondents as "experimenting with cleaning in the healthcare sector can be extremely dangerous in the event of HAI breakdown". 5 out of 12 respondents mentioned poor attitudes of the workers as a barrier in the Sri Lankan context.

According to the housekeeping managers, custodians tend to account for diverse personalities since their recruitment criteria were fairly simple and scrutinize only limited areas such as manual eligibility. This statement is substantiated by Klungseth \& Blackstad (2016) who states that cleaning is often downsized and is only focused on manual eligibility. Further respondents stated that "the lack of knowledge and understanding has made the custodians more vulnerable to unfavorable conditions. However, reluctance shown by the custodians for green cleaning over conventional cleaning makes it difficult to introduce this concept into the Sri Lankan healthcare sector". Thus, custodians' unwillingness to adapt to new concepts could have a larger impact on adopting green cleaning. In addition, the lack of competitive markets and the expensiveness of the products are highlighted as barriers to overcome the reluctant adoption of green 
cleaning. Quan et al. (2009) have pointed out the unavailability of products that causes challenges to the implementation of green cleaning. The responded facilities manager explained that higher prices of green products are a result of a lack of competitive market in Sri Lanka.

\section{Conclusions}

The rising adverse impact of conventional cleaning practices on people as well as the environment has given rise to the need for a safer and effective alternative. It has gained popularity in developed countries and numerous regulations, authorities, and guidelines have been developed to facilitate the implementation of green cleaning. It was evident that the Sri Lankan healthcare sector is gradually evolving towards green cleaning with the influence of health and environmental consideration factors. Multiple CSF of green cleaning were identified and prominent factors were:

-Proper awareness,

-Training and education,

-Top management commitment,

-Availability of green cleaning legislation and guidelines,

Prevailing barriers for implementing this novel concept were derived to comprehend the current situation and most emphasized barriers were:

-Lack of awareness of the stakeholders,

-Lack of top management commitment,

-Lack of technical advancement in the country,

-Lack of government support.

This clearly shows that the Sri Lankan cleaning industry lacks the very CSF identified by the study. Through this research, knowledge on the green cleaning concept, critical success factors of green cleaning and prevailing barriers in Sri Lankan cleaning were identified.

Through this research, knowledge on the green cleaning concept and attributed practices, identification of CSF and barriers of green cleaning in the Sri Lankan healthcare sector were elicited. Developing a socio-economic scale of green cleaning to form a basis for comparison and measuring the contribution of green cleaning of achieving sustainable goals of an organization can be identified as a potential future research area related to this area. Though the focus area of the research was the healthcare industry, both academic and industry practitioners will benefit from further research and applying the research findings for the betterment of the future of the society in Sri Lanka in particular and the globe as a whole.

\section{References}

Arif, A. A. \& Delclos, G. L., (2012) Association between cleaning-related chemicals and work-related asthma and asthma symptoms among healthcare professionals. Occupational and Environmental Medicine, 69(1), pp. 35-40.

Atamamen, F. O. et al., (2016) A Conceptual Framework of Critical Success Factors for Green Cleaning Implementation and Performance. International Journal of Real Estate Studies, 10(2), pp. 56-72.

Boyce, J. M., (2016) Modern technologies for improving cleaning and disinfection of environmental surfaces in hospitals. Antimicrobial Resistance and Infection Control, 5(10).

Chadegani, A. A. et al., (2013) A Comparison between Two Main Academic Literature Collections: Web of Science and Scopus Databases. Asian Social Science, 9(5), pp. 18-26.

Corbett, J. S., Wagner, D. \& Esbensen, P., (2017) Sustainability Guide: Global Green Cleaning. [Online] Available at: http://community.ifma.org/knowledge library/m/free fm content $/ 1057407$

Dancer, S. (2011) Hospital cleaning in the 21st century. European Journal of Clinical Microbiology \& Infectious Diseases, 30(12), pp. 1473-1481.

Dancer, S. J. (2016) Dos and don'ts for hospital cleaning. Current opinion in infectious diseases, 29(4), pp. 415-423.

Darly, M. \& Pitt, M. (2012) Environmental cleaning in UK healthcare since the NHS Plan: A policy and evidence based context. Facilities, 30(1/2), pp. 6-22.

Dumas, O. et al. (2017) Occupational exposure to disinfectants and asthma control in US nurses. European Respiratory Journal, 50(4), p. 1700237.

Durif , F., Roy, J. \& Boivin , C. (2012) Could Perceived Risks Explain the 'Green Gap' in Green Product Consumption?. Electronic Green Journal, Issue 33. 
Elizabeth, G. et al. (2013) Impact of LEED-Certified Affordable Housing on Asthma in the South Bronx. Progress in Community Health Partnerships: Research, Education, and Action, 7(1), pp. 1-10.

Environmental Protection Agency (2010). Greening your purchase of cleaning products. A guide for fedaral purchaser.

Espinoza, T., Geiger, C. \& Everson, I. (2011) The Real Costs of Institutional "Green” Cleaning.

Guz, A. N. \& Rushchitsky, J. J. (2009). Scopus: A system for the evaluation of scientific journals. International Applied Mechanics, 45(4), pp. 351-362.

Hennink, M., Hutter, I. \& Bailey, A. (2010) Qualitative Research Methods. SAGE publications.

Hsieh, H.-F. \& Shannon, S. E. (2005) Three Approaches to Qualitative Content Analysis. Qualitative Health Research, 15(9), pp. 1277-1288.

Klungseth, N. J. \& Olsson, N. O. E. (2013) Norwegian cleaning research: an overview and categorization. Facilities, 31(7/8), pp. 290-313.

Markkanen, P., Quinn, M., Galligan, C. \& Bello, A. (2009) Cleaning in Healthcare Facilities Reducing human health effects, s.l.: s.n.

Moramudali, . W. \& Manawadu, G. (2018) Adoption of Green Practices in Hotel Industry in Sri Lanka An Evaluation Based on the Green SL Rating System. s.1., s.n.

Moual, N. L. et al. (2013) Are operating room nurses at higher risk of severe persistent asthma? The Nurses' Health Study. Journal of Occupational and Environmental Medicine/American collage of Occupational and Environmental Medicine, 55(8), pp. 973-977.

Nazarof, W. W. \& Weschler, C. J. (2004) Cleaning products and air fresheners: exposure to primary and secondary air pollutants. Atmospheric Environment, 38(18), p. 2841-2865.

OSHA/NIOSH Infosheet, (2012).Protecting Workers Who Use Cleaning Chemicals, s.l.: Occupational Safety and Health Administration.

Quan, X., Joseph, A. \& Jelen, M., (2011) Green Cleaning in Healthcare: Current Practices and Questions for Future Research, s.l.: s.n.

Quinn, M. M. et al. (2015) Cleaning and disinfecting environmental surfaces in health care: Toward an integrated framework for infection and occupational illness prevention. American Journal of Infection Control, 43(5), pp. 424-434.

Ramli, N. A. et al. (2018) A perspective study on green cleaning for Malaysian public hospital. s.l., IOP Publishing, p. 012017.

Sabharwal, J. (2015) Health Issues and Environmental Impact of Cleaning Agents. International Journal of Novel Research in Life Sciences, 2(2), pp. 32-38.

Saito, R. et al. (2015) Characterization of cleaning and disinfecting tasks and product use among hospital occupations. American Journal of Industrial Medicine, 58(1), pp. 101-111.

Senier, L., Mayer, B., Brown, P. \& Frosch, R. M. (2007) School Custodians and Green Cleaners: New Approaches to Labor-Environment Coalitions. Organization \& Environment, 20(3), pp. 304-324.

Simcox, N. et al., (2013) Transitioning from Traditional to Green Cleaners: An Analysis of Custodian and Manager Focus Groups. New Solutions, 22(4), pp. 449-471.

Spruce, L., 2017. Back to Basics: Environmental Cleaning Hazards. AORN Journal, 106(5), pp. 424-432.

Vieira, E. S. \& Jose, A. N. F. G. (2009) A comparison of Scopus and Web of Science for a typical university. Scientometrics, 81(2), pp. 587-600.

Welsh, E., (2002) Dealing with Data: Using NVivo in the Qualitative Data Analysis Process. Forum: Qualitative Social Research, 3(2), pp. 1-7.

Zingg, W. et al. (2015) Hospital organisation, management, and structure for prevention of health-care-associated infection: a systematic review and expert consensus. The Lancet Infectious Diseases, 15(2), pp. 212-224. 